Article

\title{
Impact of Structural Defects on the Surface Quality of Hardwood Species Sliced Veneers
}

\author{
Vasiliki Kamperidou ${ }^{1, *} \mathbb{C}$, Efstratios Aidinidis ${ }^{2}$ and Ioannis Barboutis ${ }^{1}$ \\ 1 Department of Harvesting and Technology of Forest Products, Aristotle University of Thessaloniki, \\ 54124 Thessaloniki, Greece; jbarb@for.auth.gr \\ 2 Department of Forestry and Natural Environment Management, Agricultural University of Athens, \\ 11855 Athens, Greece; eaidinidis@aua.gr \\ * Correspondence: vkamperi@for.auth.gr; Tel.: +30-2310998895
}

Received: 20 August 2020; Accepted: 7 September 2020; Published: 9 September 2020

\begin{abstract}
The surface roughness constitutes one of the most critical properties of wood and wood veneers for their extended utilization, affecting the bonding ability of the veneers with one another in the manufacturing of wood composites, the finishing, coating and preservation processes, and the appearance and texture of the material surface. In this research work, logs of five significant European hardwood species (oak, chestnut, ash, poplar, cherry) of Balkan origin were sliced into decorative veneers. Their surface roughness was examined by applying a stylus tracing method, on typical wood structure areas of each wood species, as well as around the areas of wood defects (knots, decay, annual rings irregularities, etc.), to compare them and assess the impact of the defects on the surface quality of veneers. The chestnut veneers presented the smoothest surfaces, while ash veneers, despite the higher density, recorded the highest roughness. In most of the cases, the roughness was found to be significantly lower around the defects, compared to the typical structure surfaces, probably due to lower porosity, higher density and the presence of tensile wood. The results reveal that the presence of defects does not affect the roughness of the veneers and increases neither the processing requirements of the veneer sheets before finishing, nor the respective production cost of veneers and the veneer-based wood panels. The high utilization prospects of the examined wood species in veneer production, even those bearing various defects, is highlighted.
\end{abstract}

Keywords: chestnut; decay; defect; density; knot; roughness; surface; texture; quality; veneer

\section{Introduction}

The surface of each material or final product consists of a miniature of peaks and valleys, the size and distribution of which determine the surface properties of the material, such as roughness, texture, etc. The surface roughness is estimated in order to predict the surface behavior of the material during its application in various uses. As regards wood, roughness greatly affects its aesthetics and the structures in which it participates, and should be in line with the criteria and requirements of consumers in terms of quality. As regards wood veneer sheets, rough surfaces of veneers not only negatively affect the appearance of the finished products, but also affect manufacturing processes such as coatings and adhesion appliance, and adhesion strength, since they reduce the contact between them, resulting, according to the literature, in weak interactions between glue and wood and, therefore, low-strength properties of laminated veneer lumber, plywood and several other wood-based composites [1-3].

Due to its structure and anatomical features, the wood surface is a multidimensional and complex substrate, and its roughness is influenced by various factors such as the wood species (hardwood versus softwood), wood density and porosity (denser wood corresponds to lower porosity and smoother surfaces), annual rings' width, ratio of early wood to late wood, the log temperature during 
slicing/peeling and wood storage conditions (temperature, relative humidity), the moisture content, wood anisotropy, structure and types of cells and the kinetics of liquids-gases into its mass, as well as several mechanical and machine processing operations (sawing, sanding, planning, etc.) parameters, such as the cutting means type, knife angle and marks per centimeter, cutterhead speed, tool wear, cutting direction (longitudinal, radial and tangential), etc. [1,3-8]. Tanritanir et al. [9] revealed that steaming for $20 \mathrm{~h}$ is an ideal pre-treatment of veneers to provide smooth surfaces of both heartwood and sapwood. In general, the use of coarse-grained veneers can reduce the bonding quality by $1 / 3$, compared to smooth surface veneers [10-12]. Less rough wood surfaces exhibit better performance in the application of finishing agents, more uniform distribution of adhesive, require much lower amounts of paint/dye to cover the whole surface, while the phenomenon of resin bleeding through the face veneer is avoided [11,12]. Furthermore, according to the literature, the surface roughness of wood material decreases as the grit number of sandpaper increases from 60 to 240 [13]. Usually, the veneer production industries apply a sanding of 80-100 grit number, to keep the production cost at low levels, while the woodworkers and manufacturers further apply additional sanding processes to the veneer-based panels, once or twice, using 180 or 220 sandpapers.

The defects generally affect the appearance of the veneer sheets, making them usually less preferable for face-side application in furniture and structures [3]. A high number of defects makes the veneer be categorized as low-value and it is usually applied in back-side applications. However, the wood defects correspond to the natural appearance of wood and, especially in recent years, there has been a phenomenon of asking for artificially aged or intensely rough furniture, precisely because they refer to and remind the customer of something special and unique. Furthermore, in the recent years in which the wood of high quality has been in short supply, the rational utilization of woody biomass, even the low-value wood species bearing a high number of defects, as well as the high-quality raw-lumber saving strategy, seems to be of crucial importance.

Currently, there is no comprehensive information available concerning the way that several different wood defects affect the smoothness and surface quality of sliced veneer sheets manufactured from different hardwood species. Therefore, the purpose of this study is to examine the surface roughness parameters values of sliced veneers made of five different species significant for veneer production European hardwood species (ring-porous, semi-ring porous and diffuse porous), are investigated, for the first time according to the literature, in terms of how their roughness level is influenced by the presence of various structural defects in the mass and surface of veneers, such as knots, irregularities of annual rings structure (spiral grain), decay, discoloration etc., compared to typical structure surfaces of each wood species' veneers. Additionally, it is investigated how the surface roughness of sliced veneer sheets, continuous in row and successively cut, differentiates in different wood depths, observing the evolution of the whole defect as it is encountered in the trunk, in areas of typical and non-typical wood structure.

\section{Materials and Methods}

The raw material of this experimental work consisted of logs of five European hardwood species of Greek and Balkan origin of large diameter ( $350 \mathrm{~mm}$ mean diameter). Specifically, one log was examined per examined forest species, which were oak (Quercus robur L.), chestnut (Castanea sativa), ash (Fraxinus excelsior L.), hybrid poplar (Populous spp.) and wild cherry (Prunus avium). Only the poplar wood was of Greek origin, while the rest of the species used were obtained from 3 different Balkan countries (Romania, Croatia and Serbia), and they were all commercially converted into decorative sliced veneer sheets, using the veneer slicing method, applied in the infrastructures of a Greek industry of sliced veneer production, located in central Greece (Chalkida, Evia), so that the processing conditions, the cutting means and the slicing method applied would be common for the five wood species. The veneer production fulfilled the requirements of the industrial sliced veneer production standards of this certified company, as regards the absence of thickness inequalities, defects attributed to mechanical processing failures, like burning, etc. The trunks were initially peeled 
to remove the bark, cut into logs, and then steamed under the same conditions (duration, temperature, pressure) followed by the industry, prior to the slicing process. The cutting machine used for the slicing of veneers was of horizontal operation, since this is suitable for the veneer slicing of hardwood species and they were all cut into plain cut (flat cut) veneers. After a visual assessment of the defects on the produced veneers, for each case of wood species and defect species, a package of 10 sliced veneer sheets, continuous in a row and successively cut, was obtained, aiming to observe the evolution of the whole defect as it is encountered in the trunk mass. The veneer sheets produced were of $0.55 \pm 0.1 \mathrm{~mm}$ thickness, mainly cut from the heartwood part of trunks and for the purposes of this experiment, they were cut in our laboratory in smaller dimensions ( $350 \mathrm{~mm}$ length $\times 250 \mathrm{~mm}$ width) to be easily handled, and were left to be conditioned at $20 \pm 2{ }^{\circ} \mathrm{C}$ and $65 \pm 5 \%$ relative humidity, until constant weight. All veneer samples were conditioned to equilibrium moisture content (EMC), which ranged at low levels (5.5-10\%) [14]. Twenty days before the roughness measurements' implementation, the veneers were anchored tightly on flat surfaces and, subsequently, the veneer sheets' surfaces were slightly sanded with 80-grit sand paper for $15 \mathrm{~s}$. under the same laboratory conditions, since the sanding process creates a new and fresh surface by removing the material and, therefore, can improve the surface quality of veneers before finishing [15]. Afterwards, the veneers were removed from the abovementioned flat surfaces and left for approximately three weeks to be conditioned at $20 \pm 2{ }^{\circ} \mathrm{C}$ and $65 \pm 5 \%$ relative humidity, until constant weight. At the end of the conditioning duration, the EMC was measured again by applying the drying method of the veneer samples [14] and recording similar EMC values with those prior to the sanding and conditioning processes $(<10 \%)$. The mean density of the veneers was also measured after their conditioning process (calculated as dry mass/ wet volume, with volume measured in the state of the EMC), following the respective international standard process [16], with the only difference that specimens of different dimensions were measured $(20 \mathrm{~mm} \times 20 \mathrm{~mm} \times 0.5 \mathrm{~mm})$. For the dry mass measurement, a weight of high accuracy (of 4 decimals) was used, and for the volume determination, a digital caliper was used. The density of oak wood was found to be $0.742 \mathrm{~g} / \mathrm{cm}^{3}$, of chestnut wood was $0.554 \mathrm{~g} / \mathrm{cm}^{3}$, of ash wood was $0.705 \mathrm{~g} / \mathrm{cm}^{3}$, of poplar wood was $0.385 \mathrm{~g} / \mathrm{cm}^{3}$ and of cherry wood was $0.627 \mathrm{~g} / \mathrm{cm}^{3}$.

On the veneers, 10-12 measurements of roughness parameters were randomly implemented on the surface of typical wood structure areas and, respectively, another 10-12 measurements of roughness were conducted on non-typical wood structures of veneer surfaces in the peripheral area of each defect (10-30 $\mathrm{mm}$ radius around the defect). The defects were different for each wood species, including knots (Figure 1), tensile wood, irregular annual rings, deflection of wood fibers (spiral grain), discoloration (Figure 2), decay (Figure 3) etc., since, as with the material of wood, its defects, as well, are unique. The number of 3 to 10 different veneer sheets were measured from each veneer's package and for each wood species, in order to investigate the potential differentiation of roughness as a function of different wood depths on the defects' development areas.

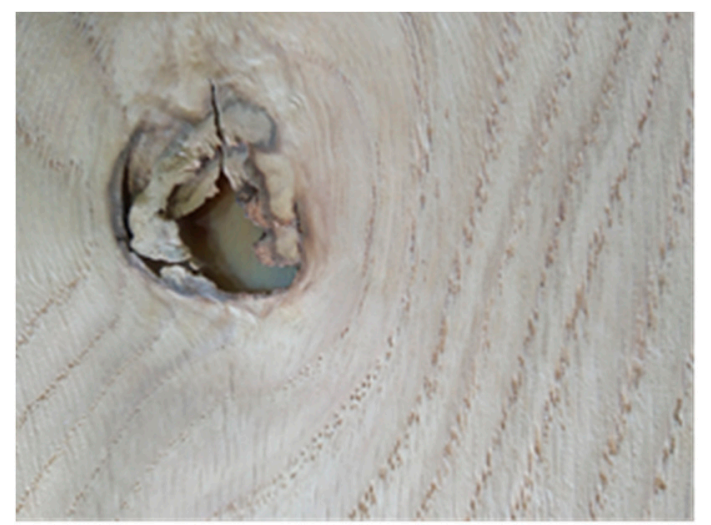

(a)

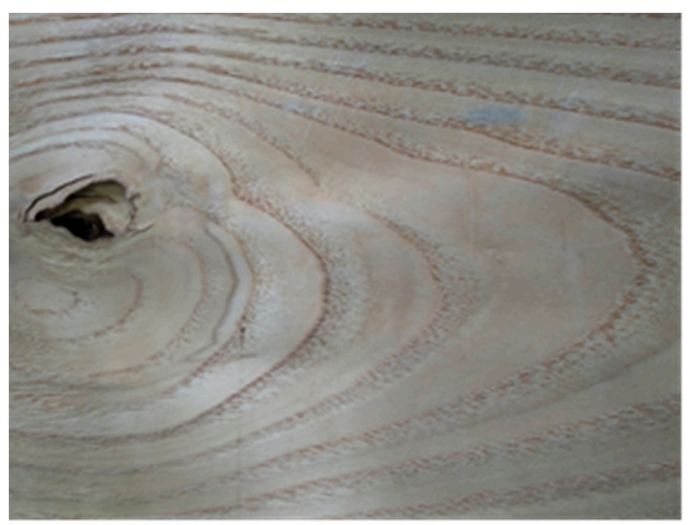

(b)

Figure 1. Dead knots in oak wood sliced plain-cut veneer (a), and in chestnut wood sliced veneer (b). 


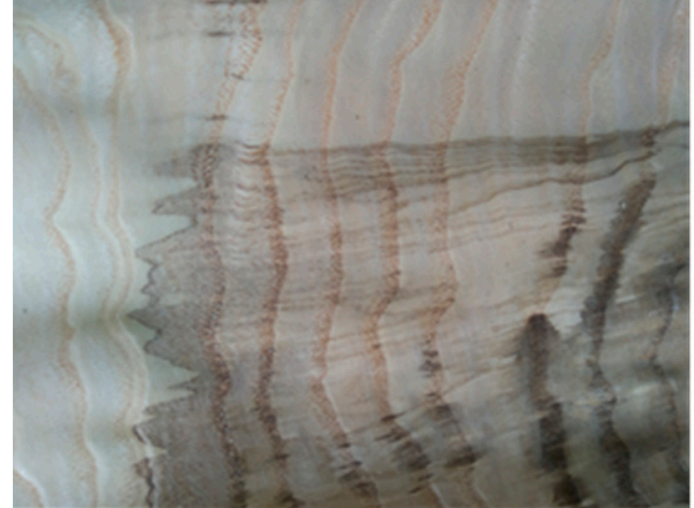

(a)

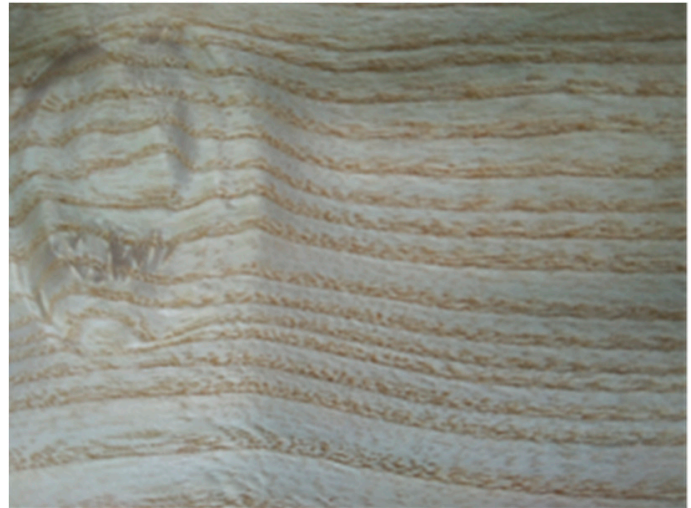

(b)

Figure 2. Ash wood sliced veneer with discoloration and irregularities of annual rings (a), and live internal knot with spiral grain around the knot $(\mathbf{b})$.

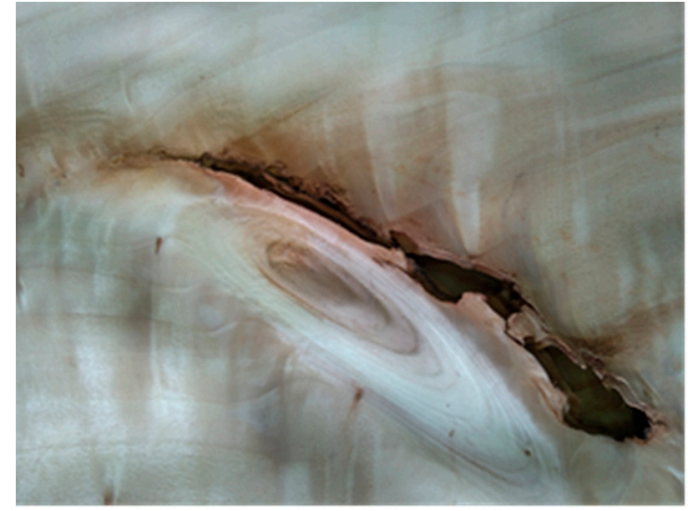

(a)

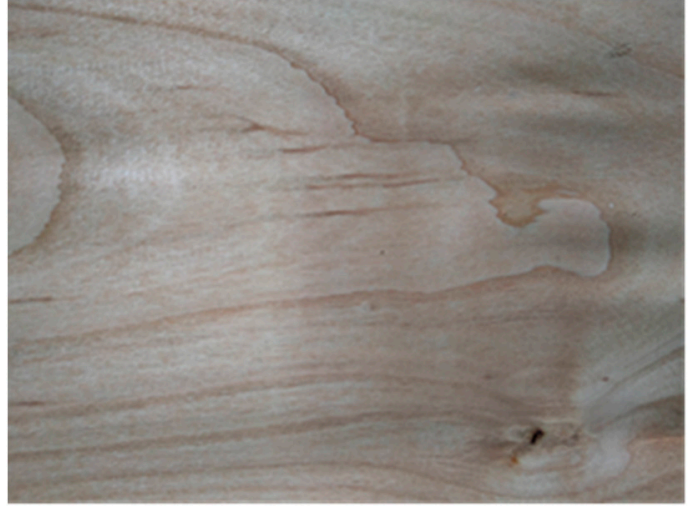

(b)

Figure 3. Poplar wood sliced plain-cut veneer sheet with live knot and decay (a), and cherry wood veneer with irregularities of annual rings (b).

The roughness parameters of the prepared veneer surfaces were evaluated using a fine stylus type profilometer, Mitutoyo Surftest SJ-301 (Figure 4), with the profile tracing method using the diamond stylus of the device, according to ISO 4287:1997 [17]. The stylus technique was determined to be used, since compared to the other methods, such as pneumatic, laser, and acoustic emission, it is accurate, practical, and repeatable [5]. The measuring speed, the diameter of the pin and the upper angle of the pin tool were $10 \mathrm{~mm} / \mathrm{min}, 4 \mu \mathrm{m}$, and $90^{\circ}$, respectively. The sampling length was of $2.5 \mathrm{~mm}$, and the evaluation length was of $12.5 \mathrm{~mm}$ (five times of the sampling length). The values of the surface roughness parameters were determined to be within $\pm 0.01 \mu \mathrm{m}$. The measurements were implemented in a direction perpendicular to the direction of grain orientation.

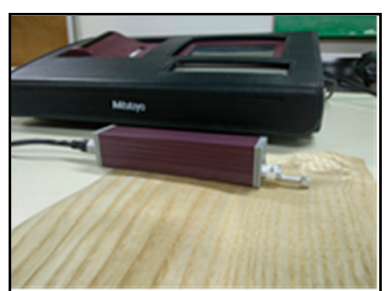

(a)

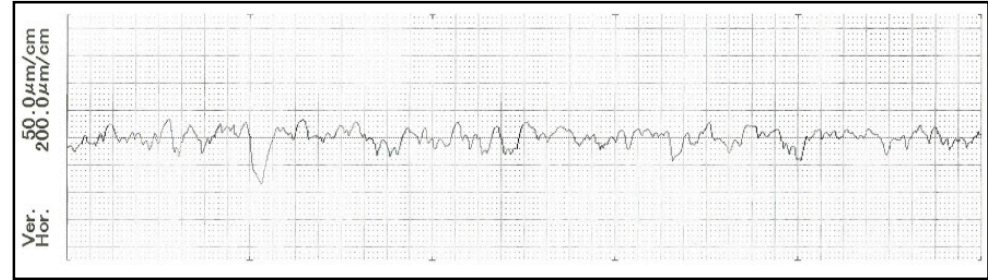

(b)

Figure 4. Roughness test using the Mitutoyo Surftest SJ-301 profilometer (a); an example of the roughness spectrum on a poplar sliced veneer sheet of typical structure (b). 
The roughness measurement points were randomly selected by marking them on the surface of the samples, in order to cover the whole area. Three roughness parameters, the mean numerical deviation from the midline profile along the entire length of the stylus movement (mean arithmetic deviation of profile-Ra), the average height between the peak-valley derived from five identical lengths of the profile (mean peak-to-valley height- $\mathrm{Rz}$ ), and the distance between peak and valley points of the profile, which can be used as an indicator of the maximum defect height within the assessed profile (maximum roughness-Ry), have been widely used in previous studies [18-20], where detailed information about these roughness parameters has been presented. These parameters, employed also in the current study, have also been used previously in the quantification of surface quality of veneers [4,21], and other wood composites, and they are defined by the respective roughness standards [17]. Prior to each measurement, the instrument was calibrated and the roughness measurements were performed at room temperature $\left(20 \pm 2{ }^{\circ} \mathrm{C}\right)[22,23]$.

For the processing and statistical analysis of the test results, the statistical package SPSS Statistics PASW 18 was used to determine the variability of the roughness parameters' mean values, and the effect of two different independent variables, "Veneers" (referring to the different veneers from V1 to V10, obtained continually and successively cut/produced as it is found in the trunk), and "Structure" (referring to the typical and non-typical structure of wood), and the potential interaction of these two factors upon the dependent variable of roughness parameter Ra (chosen as the most significant one and representative), using two way analysis of variance (ANOVA) with a significance level of $0.05(p<0.05)$.

\section{Results and Discussion}

\subsection{Veneer Surfaces of Typical Wood Structure}

According to the results (Figure 5), all the three surface roughness parameters (Ra, Rz, Ry), measured on typical wood structure surfaces, follow similar routes concerning the different wood species. The veneers of ash wood, despite their high wood density $\left(0.705 \mathrm{~g} / \mathrm{cm}^{3}\right)$, exhibited the highest surface roughness parameter values among the five species examined in this study, presenting statistically significant differences from the respective roughness values of all the other wood species veneers. The lowest roughness parameter values, and therefore, the smoother surfaces, were observed in veneers' surfaces of chestnut, whose roughness parameters' mean values were also found to differ significantly from the rest of wood species' respective values. Oak, poplar and cherry veneers recorded similar values of surface roughness parameters, even though they are characterized by much different wood density (oak $0.742 \mathrm{~g} / \mathrm{cm}^{3}$ and poplar $0.385 \mathrm{~g} / \mathrm{cm}^{3}$ ) and different structure (ring-porous/diffuse-porous/semi-ring-porous).

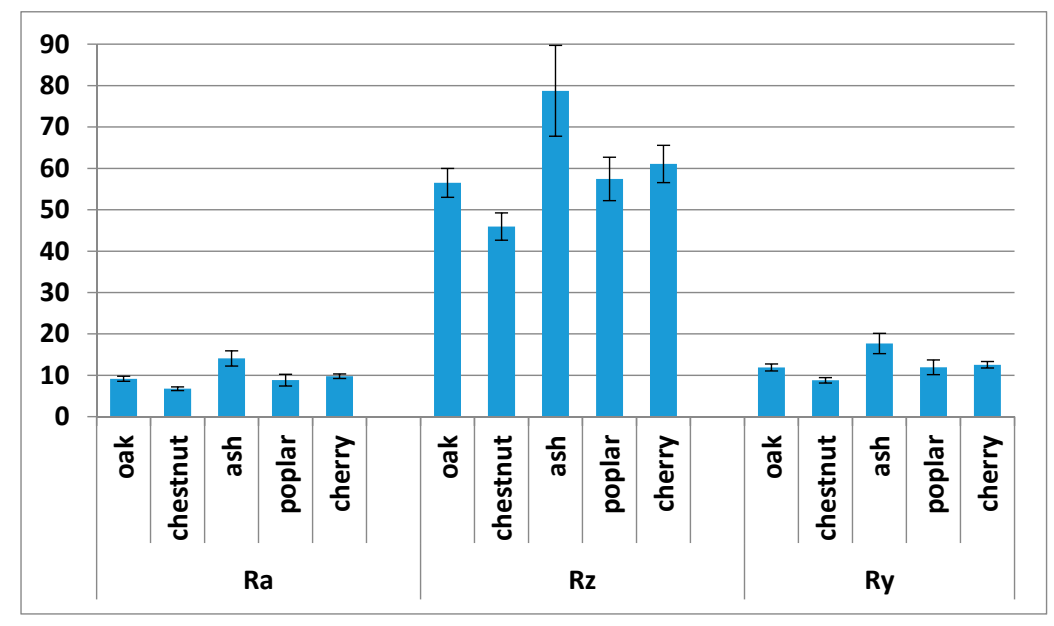

Figure 5. Mean values of surface roughness parameters Ra, Rz and Ry ( $\mu \mathrm{m})$, measured on typical wood structure areas of the sliced veneer sheets of the five different species studied. 


\subsection{Oak Veneers}

In the case of oak wood, the roughness parameters of three veneers from the oak veneers package that corresponds to the evolution of the whole knot, were chosen to be measured (Figure 6). According to the results, all the three surface roughness parameters ( $R a, R z, R y)$ were found to be, from the statistical analysis point of view, significantly lower in the case of the area around the knot, indicating a smoother area around the knot, compared to the typical structure of wood surface veneers. Generally, oak wood is a ring-porous hardwood species, whose structure, as expected, results in higher roughness levels. The lower roughness of the wood areas around the dead knot that had been felled, could be attributed to their higher density, lower porosity and the presence of tensile wood that was also visually detected. As it is widely known, tensile wood is formed on hardwoods on the upper side of logs and branches in places that are under tension. Tensile wood is characterized by lighter color and fibers that have thick walls and very small cavities. The cell walls in tensile wood areas are characterized by the presence of a gelatinous layer, which consists of concentrated microfiber substrates arranged almost parallel to the fiber axis, and can be deposited on the layer $S_{3}$ or even on layer $S_{2}$, causing the cell walls to be of higher thickness and the surface of tensile wood to become glossy [24]. Therefore, the tensile wood areas were easily recognized on the sliced veneers of this study.

According to the statistical analysis of the results, in all cases examined, the Levene tests revealed that the null hypothesis that the error variance of the dependent variable (Ra) is equal across the groups, was accepted (6th requirement of a successful ANOVA), recording a significance level $>0.05$ $(0.12-0.278)$. Investigating the roughness in different depths and areas around the knot (radius of $30 \mathrm{~mm}$ from the knot), going from veneer V1 to veneer V10, it is apparent (Table 1), that the roughness level records a slight decrease, marginally not statistically significant. The tests of Between-Subjects effects revealed that the factor of "veneers", referring to this progress of the different cutting depths from V1 to V10, affected the Ra variance by $16.4 \%$. In addition, $83.4 \%$ of Ra variance is attributed to the factor of "Structure", referring to the typical and non-typical structure of wood (the latter around the knot), while the interaction between the factors "Veneers" and "Structure" affects the Ra variance by $21.4 \%$.

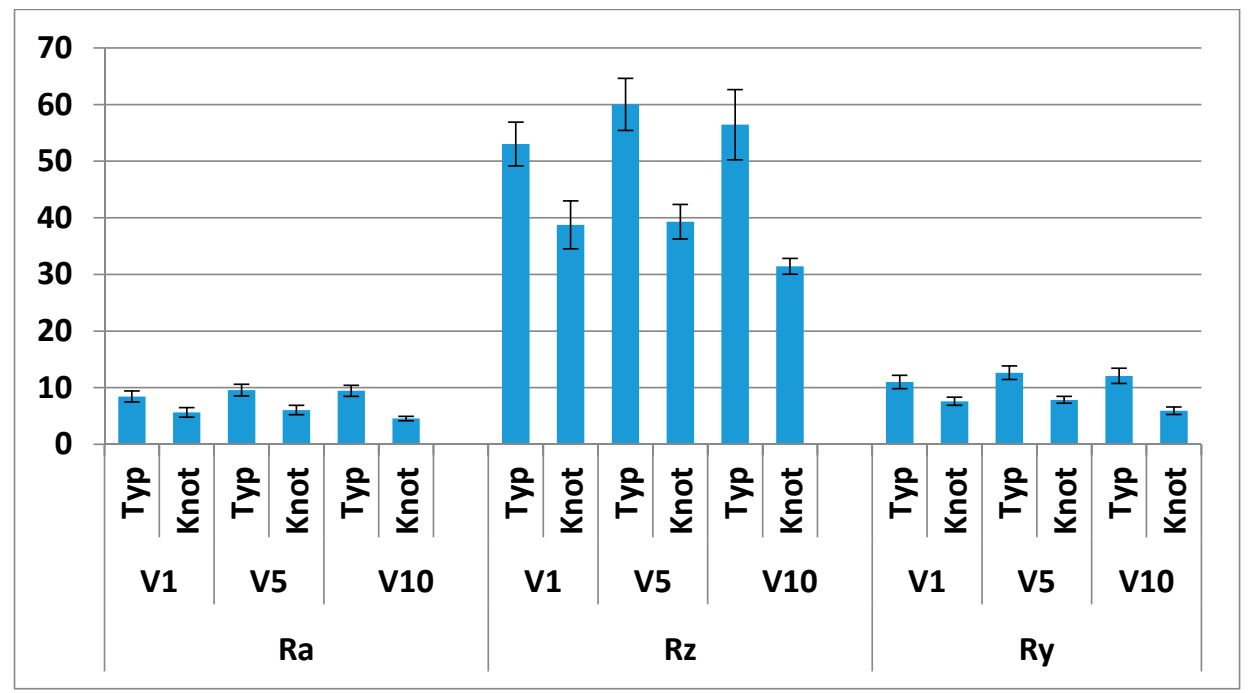

Figure 6. Surface roughness parameters $\mathrm{Ra}, \mathrm{Rz}$ and $\mathrm{Ry}(\mu \mathrm{m})$ of oak wood veneers (V1, V5 and V10) on typical wood structure areas (Typ) and areas around dead knot (Knot). 
Table 1. Descriptive statistics of dependent variable Ra measured on oak veneers of typical and non-typical structure around the knot.

\begin{tabular}{ccccc}
\hline \multicolumn{2}{c}{ Dependent Variable: $\mathbf{R a}$} & & & \\
\hline Veneers & Structure & Mean & Std. Deviation & N \\
\hline \multirow{3}{*}{ V1 } & Typical & 8.4445 & 0.97158 & 11 \\
& Knot & 5.6367 & 0.84131 & 12 \\
& Total & 6.9796 & 1.68515 & 23 \\
\hline \multirow{2}{*}{ V5 } & Typical & 9.5570 & 1.02813 & 11 \\
& Knot & 6.0482 & 0.84163 & 11 \\
& Total & 7.8026 & 2.01623 & 22 \\
V10 & Typical & 9.4528 & 0.97849 & 11 \\
& Knot & 4.5440 & 0.38021 & 10 \\
& Total & 7.1153 & 2.61815 & 21 \\
\hline \multirow{2}{*}{ Total } & Typical & 9.1514 & 1.08814 & 33 \\
& Knot & 5.4427 & 0.94755 & 33 \\
& Total & 7.2971 & 2.12520 & 66 \\
\hline
\end{tabular}

\subsection{Chestnut Veneers}

The results of roughness measurements carried out on veneers of the ring-porous hardwood species of chestnut wood (V1-V8) (Figure 7, Table 2), reveal that in six of the eight veneers studied, the roughness around the defect area was found to be lower than the respective mean roughness parameter values of typical wood structure surfaces, with only three of them corresponding to statistically significant differences. Only in the case of V6, the area around the dead knot was found to be of higher roughness than typical wood structure surfaces, but without marking a statistically significant difference. Investigating the roughness in different depths and areas around the dead knot, going from veneer V1 to veneer V10, it is evident that the roughness level records a gradual, though statistically significant, increase.

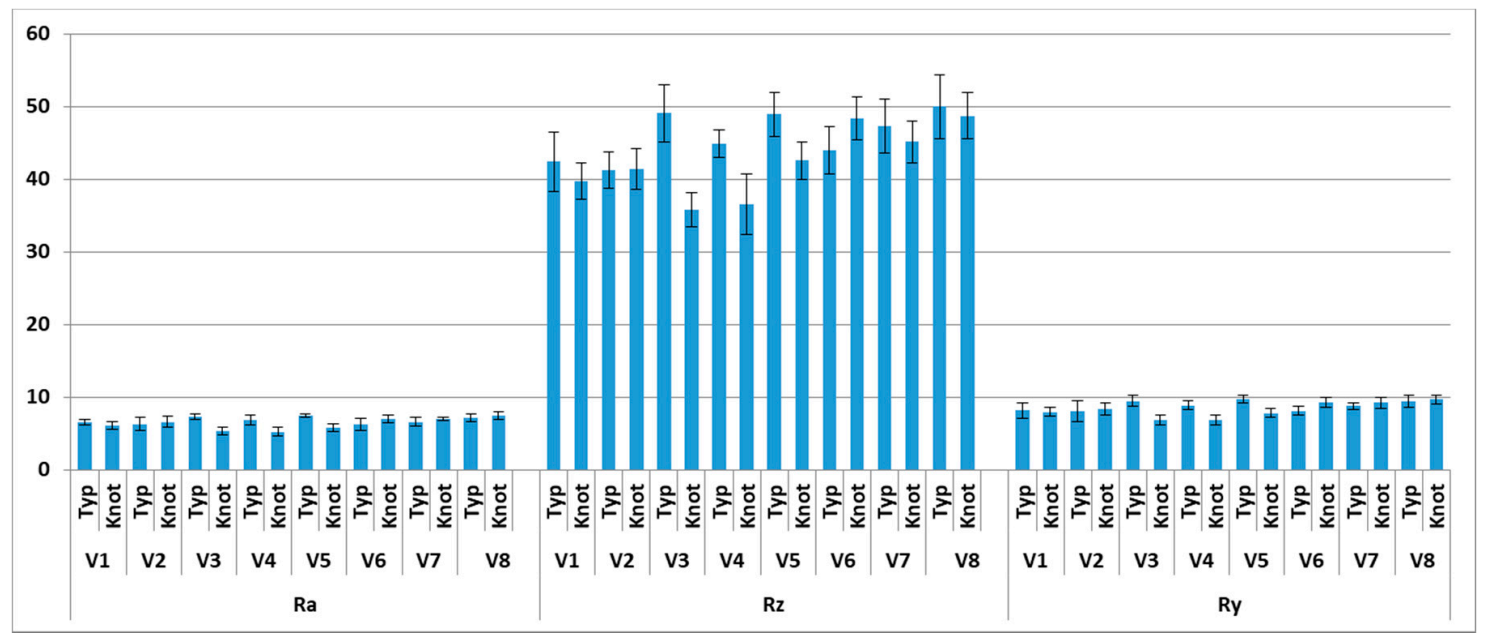

Figure 7. Surface roughness parameters $\mathrm{Ra}, \mathrm{Rz}$ and $\mathrm{Ry}(\mu \mathrm{m})$ of chestnut wood veneers (V1-V8) on typical wood structure areas and areas around dead knot.

The tests of Between-Subjects effects demonstrated that the factor of "veneers", referring to this progress of the different depths from V1 to V8, affected the Ra variance by $29.9 \%$. In addition, $15.2 \%$ of Ra variance is attributed to the factor of "Structure", referring to the typical and non-typical structure of wood (around the knot), while the interaction between the factors "Veneers" and "Structure" affects the Ra variance by $47.5 \%$. 
Table 2. Descriptive statistics of dependent variable Ra measured on chestnut veneers of typical and non-typical structure around the knot.

\begin{tabular}{|c|c|c|c|c|}
\hline \multicolumn{5}{|c|}{ Dependent Variable: $R \mathbf{R}$} \\
\hline Veneers & Structure & Mean & Std. Deviation & $\mathbf{N}$ \\
\hline \multirow{3}{*}{ V1 } & Typical & 6.5417 & 0.40739 & 10 \\
\hline & Knot area & 6.0357 & 0.55518 & 10 \\
\hline & Total & 6.2887 & 0.54037 & 20 \\
\hline \multirow{3}{*}{$\mathrm{V} 2$} & Typical & 6.2597 & 0.91630 & 10 \\
\hline & Knot area & 6.5904 & 0.74865 & 10 \\
\hline & Total & 6.4251 & 0.83185 & 20 \\
\hline \multirow{3}{*}{ V3 } & Typical & 7.2360 & 0.37384 & 10 \\
\hline & Knot area & 5.2980 & 0.49109 & 10 \\
\hline & Total & 6.2670 & 1.08112 & 20 \\
\hline \multirow{3}{*}{$\mathrm{V} 4$} & Typical & 6.8160 & 0.67526 & 10 \\
\hline & Knot area & 5.2220 & 0.65752 & 10 \\
\hline & Total & 6.0190 & 1.04375 & 20 \\
\hline \multirow{3}{*}{ V5 } & Typical & 7.4400 & 0.27227 & 10 \\
\hline & Knot area & 5.7360 & 0.56386 & 10 \\
\hline & Total & 6.5880 & 0.97459 & 20 \\
\hline \multirow{3}{*}{ V6 } & Typical & 6.2220 & 0.77334 & 10 \\
\hline & Knot area & 7.0332 & 0.52258 & 10 \\
\hline & Total & 6.6276 & 0.76539 & 20 \\
\hline \multirow{3}{*}{ V7 } & Typical & 6.5920 & 0.63405 & 10 \\
\hline & Knot area & 7.0416 & 0.24691 & 10 \\
\hline & Total & 6.8168 & 0.52202 & 20 \\
\hline \multirow{3}{*}{ V8 } & Typical & 7.0700 & 0.52286 & 10 \\
\hline & Knot area & 7.4718 & 0.53123 & 10 \\
\hline & Total & 7.2709 & 0.55286 & 20 \\
\hline \multirow{3}{*}{ Total } & Typical & 6.7722 & 0.71659 & 80 \\
\hline & Knot area & 6.3036 & 0.96310 & 80 \\
\hline & Total & 6.5379 & 0.87820 & 160 \\
\hline
\end{tabular}

\subsection{Ash Veneers}

Ash is a wood species with a ring-porous wood structure, with the apertures of vessels to potentially increase the roughness of the wood surfaces [3]. The results from the roughness parameter measurements on ash veneers' surfaces (Figure 8, Table 3) demonstrate that the surface areas with irregularities of annual rings, in four of the total five cases examined (veneers V2-V5), exhibited significantly lower roughness parameters and smoother surfaces than typical ash wood surfaces, while in only one case (veneer V1), the typical and non-typical wood structure surfaces displayed similar roughness values. The factor of "veneers", referring to this progress of the different depths from V1 to V8, statistically significantly affected the Ra variance by $23.7 \%$. In addition, $80.8 \%$ of Ra variance is attributed to the factor of "Structure", referring to the typical and non-typical structure of wood around and on the irregularities of annual rings, while the interaction between the factors "Veneers" and "Structure" affects the Ra variance by $56.6 \%$. 


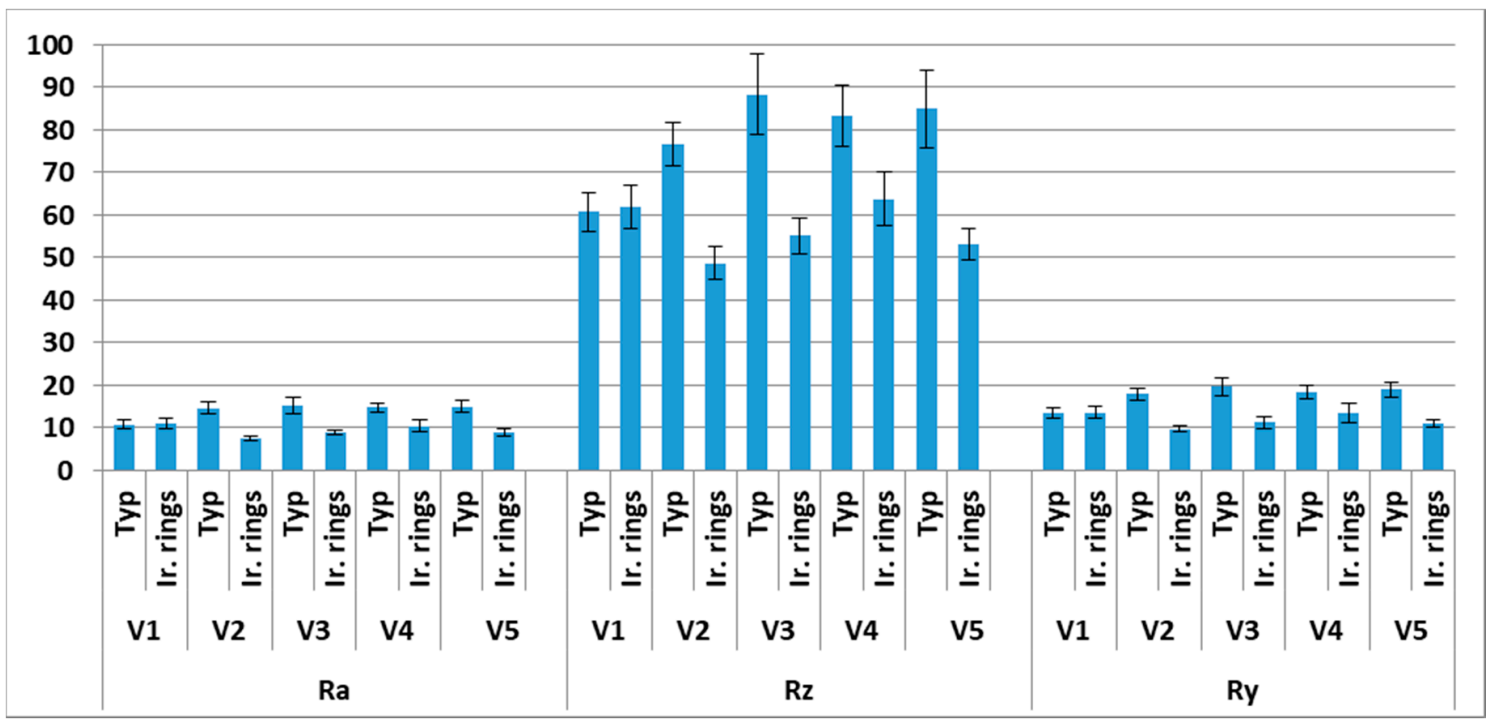

Figure 8. Surface roughness parameters $\mathrm{Ra}, \mathrm{Rz}$ and $\mathrm{Ry}(\mu \mathrm{m})$ of ash wood veneers (V1-V5) on typical wood structure areas and areas of irregular annual rings and discoloration.

Table 3. Descriptive statistics of dependent variable Ra measured on ash veneers of typical and non-typical structure on areas of irregular annual rings and discoloration.

\begin{tabular}{ccccc}
\hline \multicolumn{2}{l}{ Dependent Variable: Ra } & & & \\
\hline Veneers & Structure & Mean & Std. Deviation & N \\
\hline \multirow{2}{*}{ V1 } & Typical & 10.8020 & 1.02040 & 10 \\
& Knot area & 11.0020 & 1.17776 & 10 \\
& Total & 10.9020 & 1.07740 & 20 \\
\hline \multirow{2}{*}{ V2 } & Typical & 14.6460 & 1.45356 & 10 \\
& Knot area & 7.5680 & 0.60913 & 10 \\
& Total & 11.1070 & 3.78950 & 20 \\
\hline \multirow{2}{*}{ V3 } & Typical & 15.1980 & 1.84820 & 10 \\
& Knot area & 8.9640 & 0.61100 & 10 \\
& Total & 12.0810 & 3.46726 & 20 \\
\hline \multirow{2}{*}{ V4 } & Typical & 14.7300 & 1.19957 & 10 \\
& Knot area & 10.4760 & 1.47529 & 10 \\
& Total & 12.6030 & 2.54457 & 20 \\
\hline \multirow{2}{*}{ V5 } & Typical & 15.0300 & 1.26777 & 10 \\
& Knot area & 8.9480 & 0.77944 & 10 \\
& Total & 11.9890 & 3.28382 & 20 \\
\hline \multirow{2}{*}{ Total } & Typical & 14.0812 & 2.13308 & 50 \\
& Knot area & 9.3916 & 1.55828 & 50 \\
\hline
\end{tabular}

In the case of ash veneers obtained from the area near the trunk base, bearing discoloration and eccentric annual rings (spiral grain), statistically significant differences were not recorded between the roughness of typical and non-typical structure areas on the surface of veneers (Figure 9, Table 4). The factor of "veneers", referring to this progress of the different depths from V1 to V10, statistically significantly affected the Ra variance by $41.4 \%$. In addition, $15.9 \%$ of Ra variance is attributed to the factor of "Structure", referring to the typical and non-typical structure of wood around and on the irregularities of annual rings, while the interaction between the factors "Veneers" and "Structure" affects the Ra variance by $28.3 \%$. 


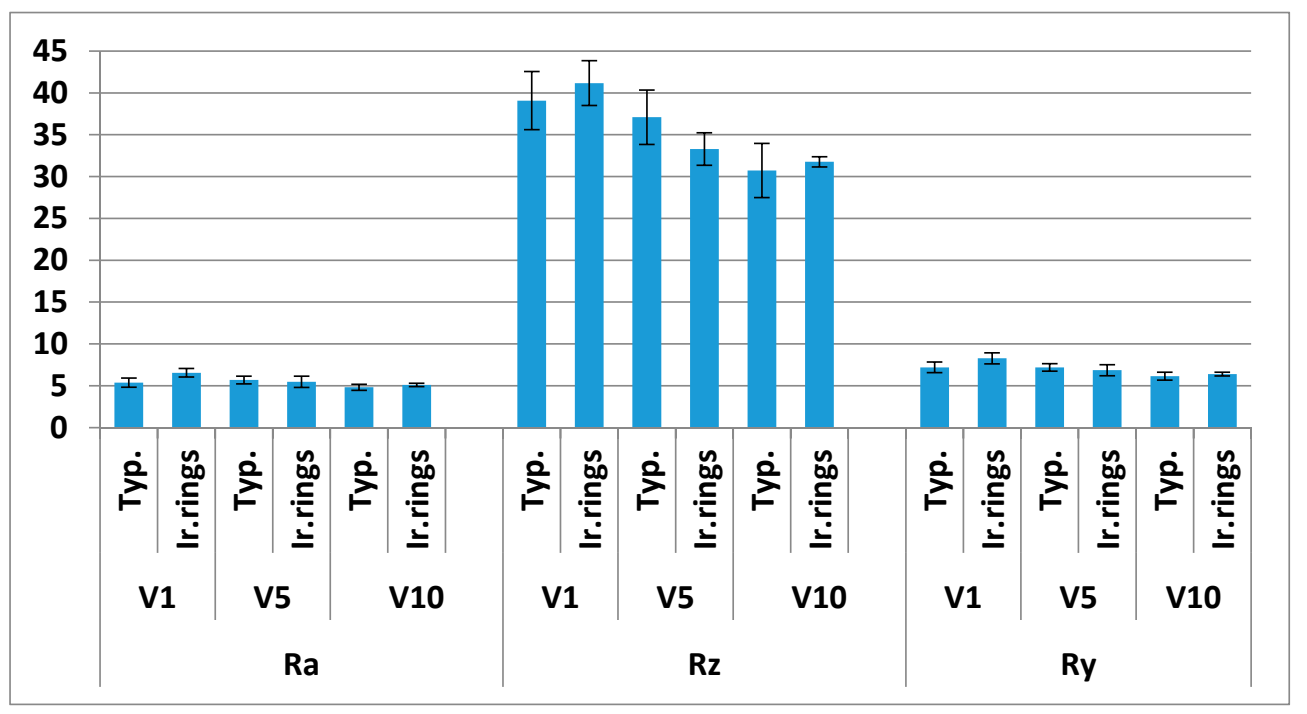

Figure 9. Surface roughness parameters $\mathrm{Ra}, \mathrm{Rz}$ and $\mathrm{Ry}(\mu \mathrm{m})$ of ash heartwood veneers $(\mathrm{V} 1, \mathrm{~V} 5, \mathrm{~V} 10)$ on typical wood structure areas and in areas of eccentric annual rings (spiral grain) of the wood near the trunk base, also bearing discoloration.

Table 4. Descriptive statistics of dependent variable Ra measured on ash stump veneers of typical wood structure areas and areas of eccentric annual rings and discoloration.

\begin{tabular}{ccccc}
\hline \multicolumn{2}{c}{ Dependent Variable: Ra } & & & \\
\hline Veneers & Structure & Mean & Std. Deviation & N \\
\hline \multirow{2}{*}{ V1 } & Typical & 5.3760 & 0.54929 & 10 \\
& Irr.rings & 6.5480 & 0.51903 & 10 \\
& Total & 5.9620 & 0.79498 & 20 \\
\hline \multirow{2}{*}{ V5 } & Typical & 5.6860 & 0.45634 & 10 \\
& Irr.rings & 5.4680 & 0.67166 & 10 \\
& Total & 5.5770 & 0.56995 & 20 \\
V10 & Typical & 4.8020 & 0.36039 & 10 \\
& Irr.rings & 5.1000 & 0.20219 & 6 \\
& Total & 4.9137 & 0.33728 & 16 \\
\hline \multirow{2}{*}{ Total } & Typical & 5.2880 & 0.58079 & 30 \\
& Irr.rings & 5.7985 & 0.80812 & 26 \\
& Total & 5.5250 & 0.73531 & 56 \\
\hline
\end{tabular}

\subsection{Poplar Veneers}

Poplar is a fast-growing diffuse-porous hardwood species of high availability, whose utilization is restricted by its low density [3]. As regards the poplar wood veneers (Figure 10), the surface roughness parameters in the areas around the decay were found to be, in most of the cases (veneers V1, V3, V4 and V5), of lower surface roughness, compared to the wood surface of typical structures. Specifically, in the case of veneers V1 and V5, the differences were found to be statistically significant, with the roughness values of areas around decay to be the lowest ones (Table 5). The tests of Between-Subjects effects revealed that the factor of "veneers", referring to this progress of the different depths from V1 to V5, significantly affected the Ra variance, by $39 \%$. In addition, $52.4 \%$ of Ra variance is attributed to the factor of "Structure", referring to the typical and non-typical structure of wood (around the decay area), while the interaction between the factors "Veneers" and "Structure" significantly affects the Ra variance, by $59.1 \%$. 


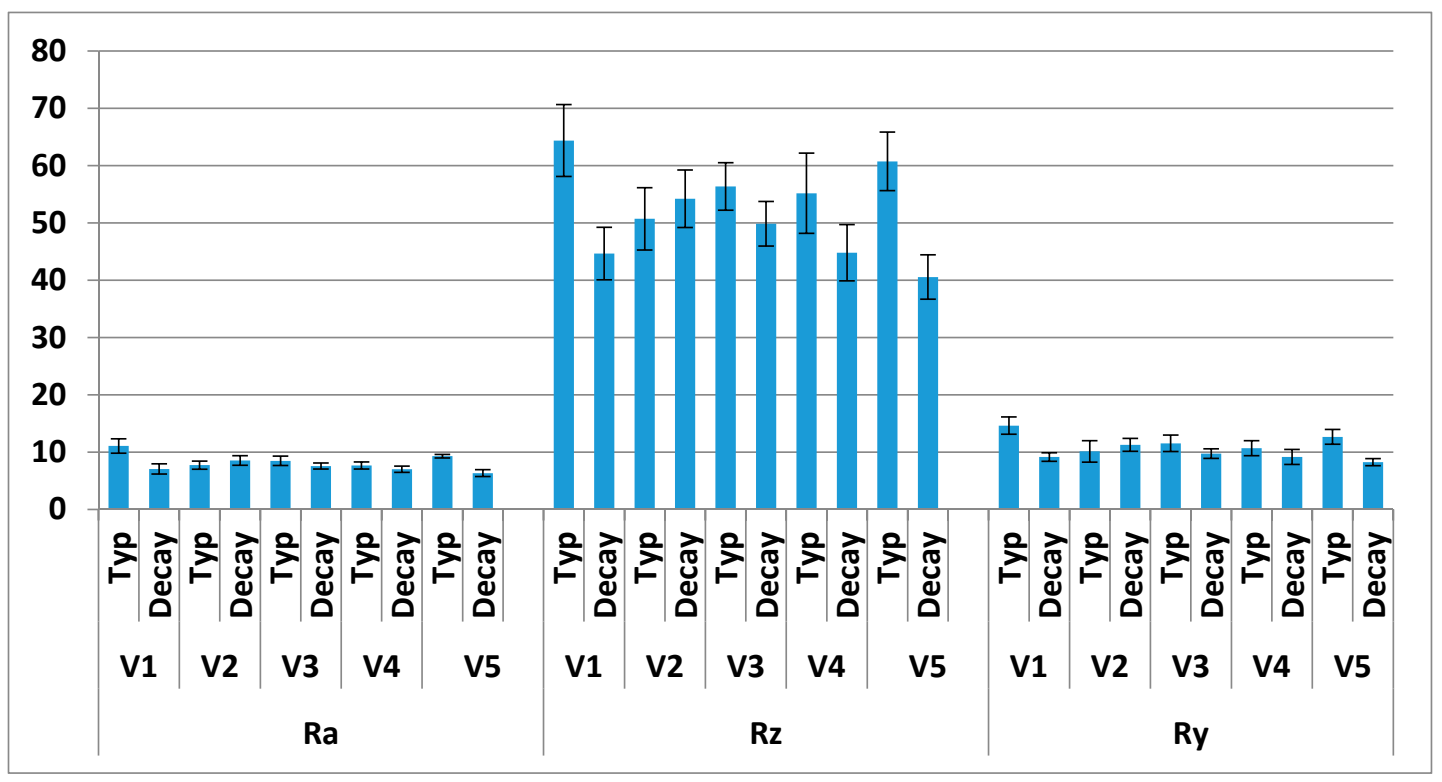

Figure 10. Surface roughness parameters $\mathrm{Ra}, \mathrm{Rz}$ and $\mathrm{Ry}(\mu \mathrm{m})$ of poplar wood veneers (V1-V5) on typical wood structure areas and around areas of decay.

Table 5. Descriptive statistics of dependent variable Ra measured on poplar veneers of typical wood structure areas and areas of decay.

\begin{tabular}{ccccc}
\hline \multicolumn{2}{l}{ Dependent Variable: $\mathbf{R a}$} & & & \\
\hline Veneers & Structure & Mean & Std. Deviation & N \\
\hline \multirow{2}{*}{ V1 } & Typical & 11.0760 & 1.25466 & 10 \\
& Decay & 7.0540 & 0.89370 & 10 \\
& Total & 9.0650 & 2.31969 & 20 \\
\hline \multirow{2}{*}{ V2 } & Typical & 7.7180 & 0.70577 & 10 \\
& Decay & 8.5400 & 0.83865 & 10 \\
& Total & 8.1290 & 0.86424 & 20 \\
\hline \multirow{2}{*}{ V3 } & Typical & 8.4760 & 0.80899 & 10 \\
& Decay & 7.5660 & 0.52812 & 10 \\
& Total & 8.0210 & 0.81244 & 20 \\
\hline \multirow{2}{*}{ V4 } & Typical & 7.6540 & 0.61401 & 10 \\
& Decay & 7.0120 & 0.53705 & 10 \\
& Total & 7.3330 & 0.65089 & 20 \\
\hline \multirow{2}{*}{ V5 } & Typical & 9.2900 & 0.31035 & 6 \\
& Decay & 6.3250 & 0.59409 & 8 \\
& Total & 7.5957 & 1.59551 & 14 \\
\hline \multirow{2}{*}{ Total } & Typical & 8.8039 & 1.54594 & 46 \\
& Decay & 7.3400 & 0.99082 & 48 \\
\hline
\end{tabular}

Concerning the roughness parameter values measured on the surface of poplar wood veneers (Figure 11, Table 6), around typical and non-typical wood structure areas, it was also revealed that the areas around the live knot detected were found to be, in each case, of significantly lower surface roughness compared to those of typical structure. The factor of "veneers", referring to this progress of the different depths from V1 to V5, significantly affected the Ra variance, by $70.4 \%$. In addition, $60.9 \%$ of Ra variance is attributed to the factor of "Structure", referring to the typical and non-typical structure of wood around and on the irregularities of annual rings, while the interaction between the 
factors "Veneers" and "Structure" was not found to be statistically significant and it affects the Ra variance only by $3.2 \%$.

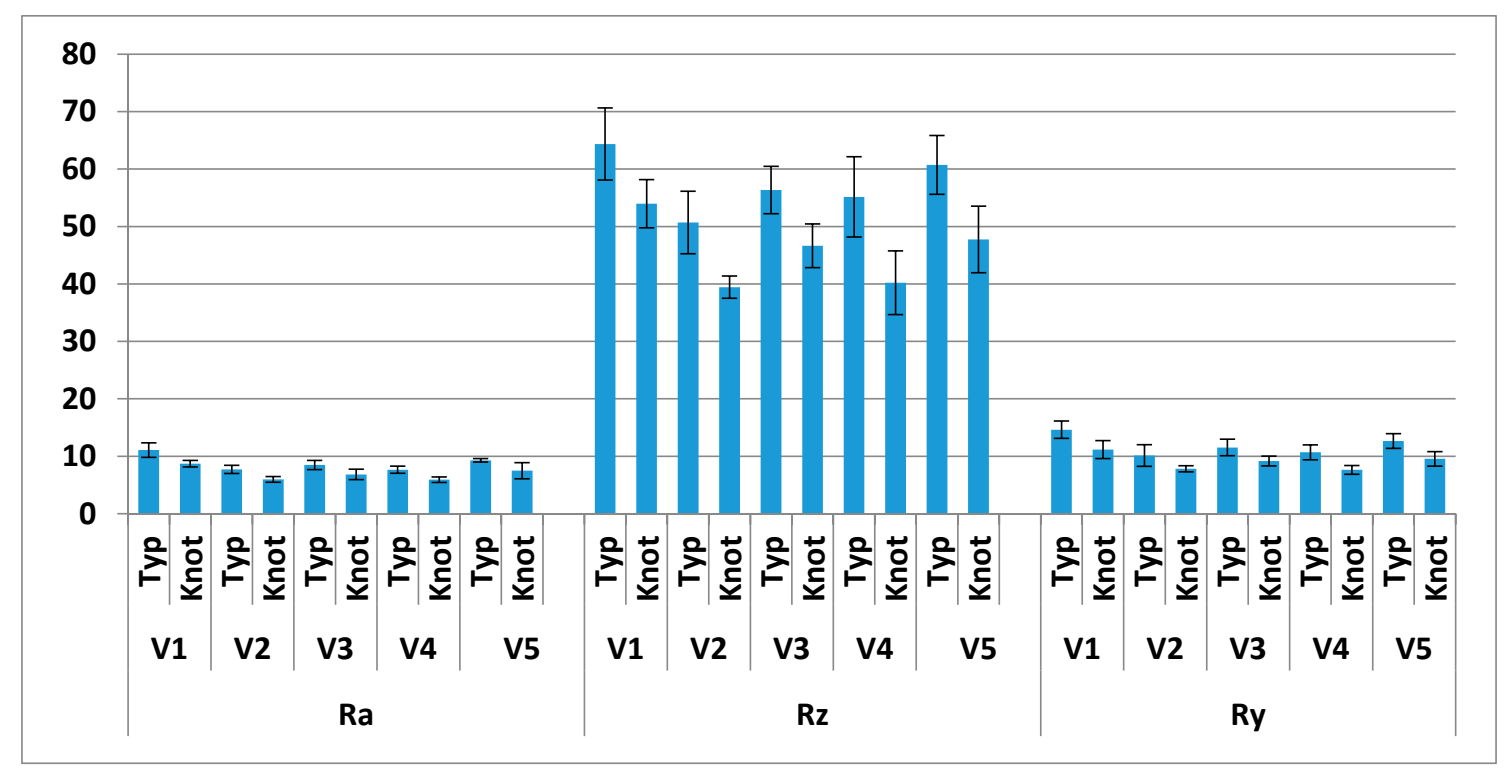

Figure 11. Surface roughness parameters $\mathrm{Ra}, \mathrm{Rz}$ and $\mathrm{Ry}(\mu \mathrm{m})$ of poplar wood veneers (V1-V5) on typical wood structure areas and areas around live knots.

Table 6. Descriptive statistics of dependent variable Ra measured on poplar veneers of typical wood structure areas and areas around a live knot.

\begin{tabular}{ccccc}
\hline \multicolumn{2}{l}{ Dependent Variable: $\mathbf{R a}$} & & & \\
\hline Veneers & Structure & Mean & Std. Deviation & N \\
\hline \multirow{2}{*}{ V1 } & Typical & 11.0760 & 1.25466 & 10 \\
& Knot area & 8.7100 & 0.55913 & 10 \\
& Total & 9.8930 & 1.53847 & 20 \\
\hline \multirow{2}{*}{ V2 } & Typical & 7.7180 & 0.70577 & 10 \\
& Knot area & 5.9720 & 0.50037 & 10 \\
& Total & 6.8450 & 1.07554 & 20 \\
V3 & Typical & 8.4760 & 0.80899 & 10 \\
& Knot area & 6.8320 & 0.91609 & 10 \\
& Total & 7.6540 & 1.19113 & 20 \\
\hline \multirow{2}{*}{ V4 } & Typical & 7.6540 & 0.61401 & 10 \\
& Knot area & 5.9200 & 0.48885 & 10 \\
& Total & 6.7870 & 1.04069 & 20 \\
\hline \multirow{2}{*}{ V5 } & Typical & 9.2900 & 0.31035 & 6 \\
& Knot area & 7.1913 & 1.25355 & 8 \\
& Total & 8.0907 & 1.42999 & 14 \\
\hline \multirow{2}{*}{ Total } & Typical & 8.8039 & 1.54594 & 46 \\
& Knot area & 6.9140 & 1.28380 & 48 \\
\hline
\end{tabular}

\subsection{Cherry Wood Veneers}

Furthermore, the roughness parameters of three veneers (V1, V5, V10) made of the semi-ring porous cherry wood were investigated (Figure 12, Table 7), revealing in each case lower surface roughness in the areas of annual rings with irregularities, compared to surface areas of typical wood structures. Nevertheless, only in the case of veneer V1, the difference between the typical structure's 
wood surface and irregular annual rings' surface was found to be statistically significant. Statistically significant differences between the roughness parameter values of the defect areas of different veneers (going from veneer V1 to V10) were not found. More specifically, the tests of Between-Subjects effects revealed that the factor of "veneers", referring to this progress of the different depths from V1 to V5, insignificantly affected the Ra variance, by 5\%. The factor of "Structure" (typical and non-typical structure) around and on the irregular annual rings, affects the Ra variance significantly by $62.4 \%$, while the interaction between the factors "Veneers" and "Structure" does not significantly affect the Ra variance (14.1\%).

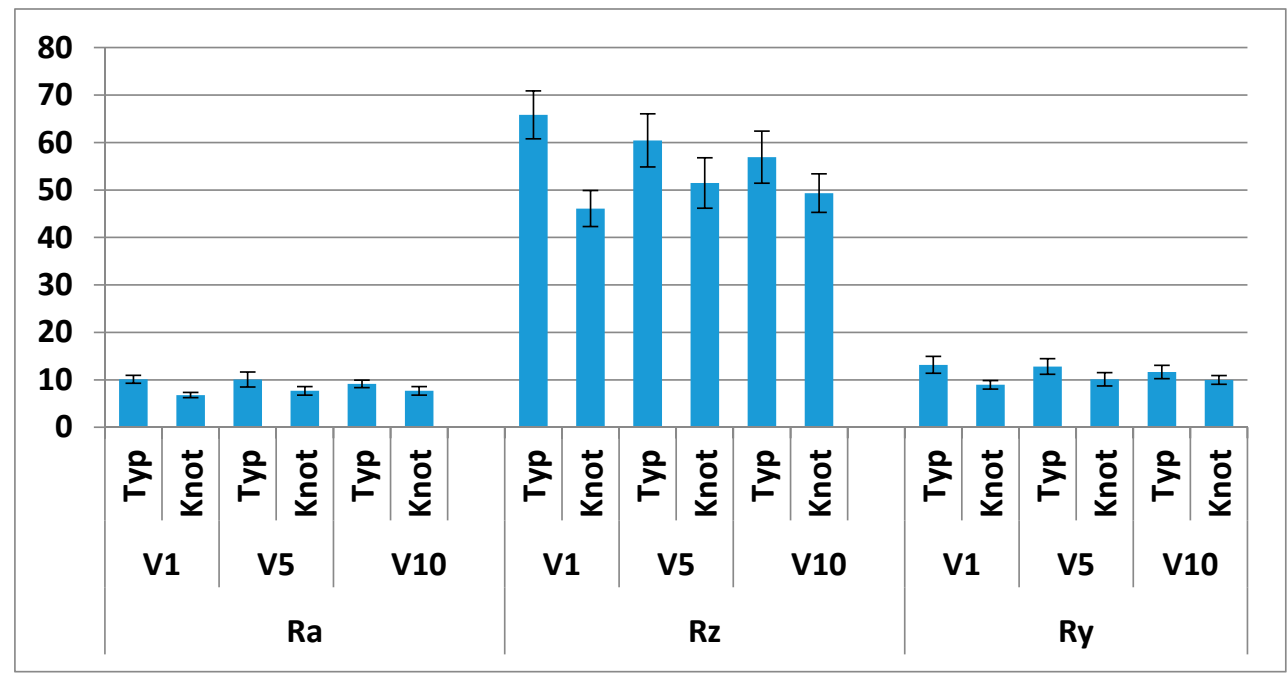

Figure 12. Surface roughness parameters $\mathrm{Ra}, \mathrm{Rz}$ and $\mathrm{Ry}(\mu \mathrm{m})$ of cherry wood veneers (V1, V5, V10) on typical wood structure areas and around areas of irregular rings.

Table 7. Descriptive statistics of dependent variable Ra measured on cherry veneers of typical wood structure areas and areas around areas of irregular rings.

\begin{tabular}{ccccc}
\hline \multicolumn{2}{c}{ Dependent Variable: $R \mathbf{a}$} & & & \\
\hline Veneers & Structure & Mean & Std. Deviation & N \\
\hline \multirow{2}{*}{ V1 } & Typical & 10.1200 & 0.82847 & 10 \\
& Knot area & 6.7960 & 0.54060 & 10 \\
& Total & 8.4580 & 1.83608 & 20 \\
\hline \multirow{2}{*}{ V5 } & Typical & 10.0760 & 1.56220 & 10 \\
& Knot area & 7.6860 & 0.89091 & 10 \\
& Total & 8.8810 & 1.74217 & 20 \\
V10 & Typical & 9.1450 & 0.78999 & 8 \\
& Knot area & 7.6800 & 0.90488 & 10 \\
& Total & 8.3311 & 1.11873 & 18 \\
\hline \multirow{2}{*}{ Total } & Typical & 9.8257 & 1.18180 & 28 \\
& Knot area & 7.3873 & 0.87864 & 30 \\
& Total & 8.5645 & 1.60158 & 58 \\
\hline
\end{tabular}

\subsection{Differences between Roughness of Typical Wood Structure and Non-Typical Structure of Defects Veneer Surfaces}

Concerning the veneers of the five hardwood species examined, their roughness was found to be lower in each case in the areas around the defects, compared to typical structure wood areas (Figure 13). Even though oak veneers did not present the highest level of surface roughness among the species examined, they demonstrated the highest difference of roughness parameters, recorded between areas of typical structure and non-typical wood structure (mean decrease of $38.84 \%$ compared 
to the reference material). Ash wood veneers, which exhibited the higher roughness values among the five species, recorded a quite high difference between the roughness levels of typical and non-typical wood structure areas (mean decrease of $31.59 \%$ ). Chestnut veneers, which generally recorded the lowest surface roughness among the five species studied, also presented the lowest difference between the roughness parameters of the typical and non-typical structure areas (mean decrease in roughness of $7.11 \%$ compared to control). Poplar and cherry wood veneers recorded a medium level decrease in roughness in areas around the defects in relation to the typical structure areas that ranged between $18.77 \%$ and $21.88 \%$.

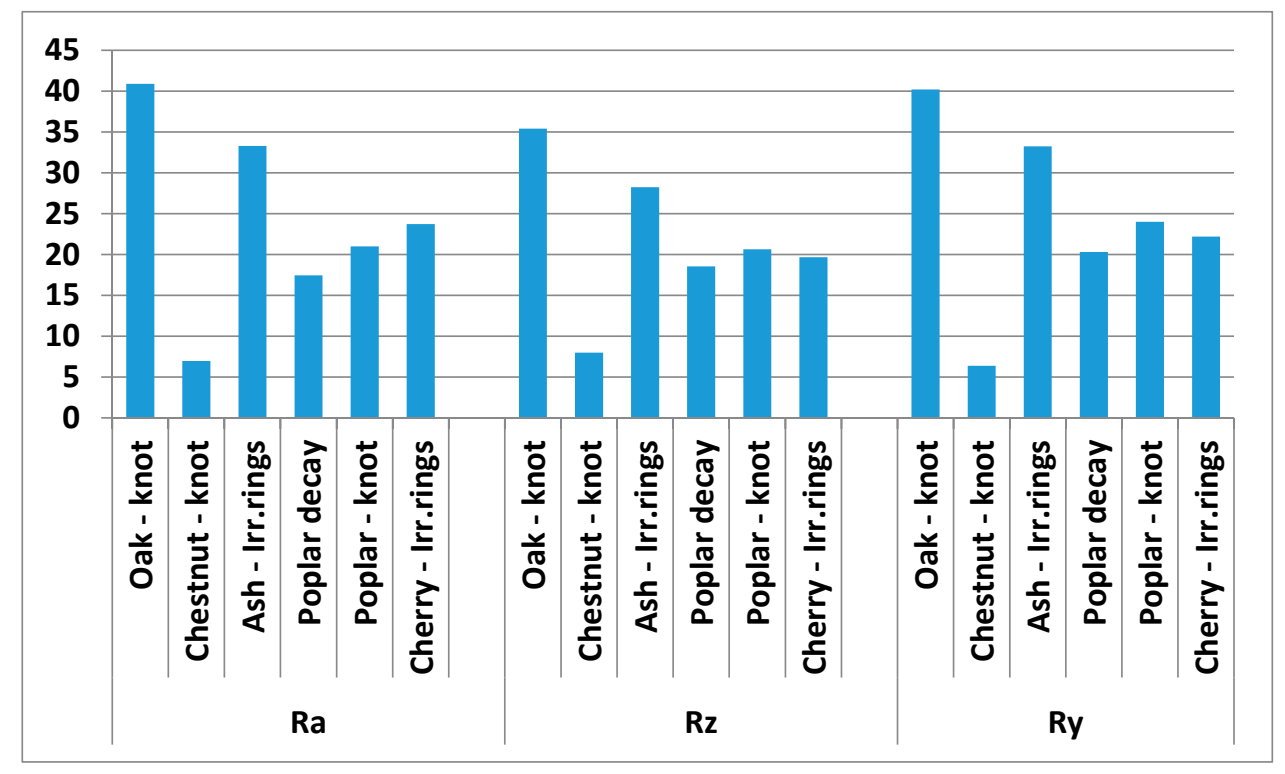

Figure 13. Percentage values depicting the differences between roughness parameters Ra, Rz and Ry of typical wood structure veneer surfaces and non-typical structure areas around the defects (decreased around the defects).

\section{Conclusions}

In this study, sliced veneers of five different European hardwood species of high significance were commercially produced and conditioned under the same conditions, to investigate the surface roughness of them in areas of typical wood structure and non-typical wood structure, in areas around defects. The chestnut species presented the lowest surface roughness among the five species studied, demonstrating the smoother surfaces, while ash wood veneers recorded the highest roughness, despite the high wood density. Although the chestnut wood studied in this experimental work was of lower density, its veneers presented smoother surfaces, compared to the other species, and this fact reveals the potential of utilizing this valuable species even more intensively in veneer production. Since the veneers were processed and conditioned under the same conditions, it is indicated by the results that density is a significant factor, but not the only one, affecting the smoothness of the veneer surfaces. Other morphological characteristics of wood, as well as the slightly different EMC of the different wood species veneers, probably have more influence on the smoothness and surface quality.

According to the results of the surface roughness parameter measurements, almost all the areas around the different defects recorded lower surface roughness values compared to typical structure areas, which could be possibly attributed to the different structure, lower porosity, higher density, presence of tensile wood, etc., in the areas around the defects. The smoothness of these surface areas around the defects indicates that the defects increase neither the roughness of surfaces, nor the processing requirements of the veneers, and therefore, do not increase the cost of veneer production. The veneers bearing several defects should not be considered as low-value and useless, but equally valuable, since they can be utilized in a wide range of applications, applying them on the backside of 
furniture and structures, or after cutting and removing the area of the defect and substituting it with another one of typical structure, or maintaining the unique appearance of the defect in the structure if possible. These data and findings were obtained through our first experimental attempt in this wide scientific field and the respective preliminary tests conducted in the frame of a project, while further studies will certainly follow from our research team, as well as the research community, in the near future, clarifying the impact of defects on the surface quality of sliced veneers and contributing to the comprehensive understanding of such veneers' final application and the respective manufactured veneer-based structures' and panels' performances. In the future, it is proposed that the effect of a single type of defect on the roughness and surface quality of a single wood species will be thoroughly investigated, examining several different logs.

Author Contributions: Conceptualization, E.A.; methodology, E.A. and I.B.; experimental work/measurements, V.K.; resources, E.A.; data curation, V.K.; writing—original draft preparation, V.K.; writing—review and editing, E.A. and I.B.; supervision, E.A. and I.B. All authors have read and agreed to the published version of the manuscript.

Funding: This research received no external funding.

Conflicts of Interest: The authors declare no conflict of interest.

\section{References}

1. Aydin, I.; Colakoglu, G.; Hiziroglu, S. Surface characteristics of spruce veneers and shear strength of plywood as a function of log temperature in peeling process. Int. J. Solids Struct. 2006, 43, 6140-6147. [CrossRef]

2. Coelho, C.L.; Carvalho, L.M.H.; Martins, J.M.; Costa, C.A.V.; Masson, D.; Meausoone, P.J. Method for evaluating the influence of wood machining conditions on the objective characterization and subjective perception of a finished surface. Wood Sci. Technol. 2008, 42, 181-195. [CrossRef]

3. Bao, M.; Huang, X.; Zhang, Y.; Yu, W.; Yu, Y. Effect of density on the hygroscopicity and surface characteristics of hybrid poplar compreg. J. Wood Sci. 2016, 62, 441-451. [CrossRef]

4. Ilter, E.; Camliyurt, C.; Balkiz, O. Research on the determination of the surface roughness values of bormulleriana fir (Abies bornmulleriana Mattf.). In Technology Bulletin; Central Anatolia Forestry Research Institute: Ankara, Turkey, 2002; p. 48.

5. Unsal, O.; Ayrilmis, Y.; Korkut, S. Effect of drying temperature on surface roughness of beech (Fagus orientalis Lipsky L.) Veneer. In Proceedings of the 9th International IUFRO Wood Drying Conference, Nanjing, China, 21-26 August 2005; pp. 316-319.

6. Magoss, E. General regularities of wood surface roughness. Acta. Silv. Lign. Hung. 2008, 4, 81-93. Available online: https://pdfs.semanticscholar.org/809d/96f71527243326b0e8d1102f3aaf5f8a2f5c.pdf (accessed on 10 July 2020).

7. Sofuoğlu, S.D.; Kurtoğlu, A. Some machining properties of 4 wood species grown in Turkey. Turk. J. Agric. For. 2014, 38, 420-427. [CrossRef]

8. Csanády, E.; Magoss, E.; Tolvaj, L. Surface Roughness of Wood. In Quality of Machined Wood Surfaces; Springer International Publishing: Cham, Switzerland, 2015; pp. 183-236. ISBN 978-319-22418-3.

9. Tanritanir, E.; Hiziroglu, S.; As, N. Effect of steaming time on surface roughness of beech veneer. Build. Environ. 2006, 41, 1494-1497. [CrossRef]

10. Faust, T.D. Real time measurement of veneer surface roughness by image analysis. Forest Prod. J. 1987, 37, 34-40.

11. Dundar, T.; Akbulut, T.; Korkut, S. The effects of some manufacturing factors on surface roughness of sliced Makoré (Tieghemella heckelii Pierre Ex A.Chev.) and rotary-cut beech (Fagus orientalis L.) veneers. Build. Environ. 2008, 43, 469-474. [CrossRef]

12. Bekhta, P.; Hiziroglu, S.; Shepelyuk, O. Properties of plywood manufactured from compressed veneer as building material. Mater. Des. 2009, 30, 947-953. [CrossRef]

13. Hendarto, B.; Shayan, E.; Ozarska, B.; Carr, R. Analysis of roughness of a sanded wood surface. Int. J. Adv. Manuf. Tech. 2006, 28, 775-780. [CrossRef]

14. ISO 13061-1:2014. Physical and Mechanical Properties of Wood-Test Methods for Small ClearWood Specimens-Part 1: Determination of Moisture Content for Physical and Mechanical Tests; ISO: Geneva, Switzerland, 2014. 
15. Demirkir, C.; Aydin, I.; Colak, S.; Colakoglu, C. Effects of plasma treatment and sanding process on surface roughness of wood veneers. Turk. J. Agric. For. 2014, 38, 663-667. [CrossRef]

16. ISO 13061-2:2014. Physical and Mechanical Properties of Wood-Test Methods for Small ClearWood Specimens-Part 2: Determination of Density for Physical and Mechanical Tests; ISO: Geneva, Switzerland, 2014.

17. ISO 4287:1997. Geometrical Product Specifications (GPS)—Surface Texture: Profile Method-Terms, Definitions and Surface Texture Parameters; ISO: Geneva, Switzerland, 1997.

18. Budakci, M.; Cemil Ilce, A.; Gurleyen, T.; Uter, M. Determination of the surface roughness of Heat-treated wood materials planed by the cutters of the horizontal milling machine. Bioresources 2013, 8, 3189-3199. [CrossRef]

19. Kamperidou, V.; Barboutis, I. Mechanical strength and surface roughness of thermally modified poplar wood. PRO Ligno 2017, 13, 107-114. Available online: http://www.proligno.ro/en/articles/2017/201704.htm (accessed on 30 December 2017).

20. Li, G.; Wu, Q.; He, Y.; Liu, Z. Surface roughness of thin wood veneers sliced from laminated green wood lumber. Maderas. Cienc. Tecnol. 2018, 20, 3-10. [CrossRef]

21. Mummery, L. Surface Texture Analysis; Hommelwerke: Muhlhausen, Germany, 1993; p. 106.

22. Korkut, D.S.; Korkut, S.; Bekar, I.; Budakçı, M.; Dilik, T.; Çakıcıer, N. The effects of heat treatment on the physical properties and surface roughness of turkish hazel (Corylus colurna L.) wood. Int. J. Mol. Sci. 2008, 9, 1772-1783. [CrossRef] [PubMed]

23. Korkut, S.; Budakci, M. The effects of high-temperature heat-treatment on physical properties and surface roughness of Rowan (Sorbus aucuparia L.) wood. Wood Res. 2010, 55, 67-78. Available online: http: //www.woodresearch.sk/wr/201001/08.pdf (accessed on 30 October 2010).

24. Filippou, I. Chemistry and Chemical Technology of Wood; Giahoudi-Giapouli Publications: Thessaloniki, Greece, $2014 ;$ p. 357.

(C) 2020 by the authors. Licensee MDPI, Basel, Switzerland. This article is an open access article distributed under the terms and conditions of the Creative Commons Attribution (CC BY) license (http://creativecommons.org/licenses/by/4.0/). 